V. 13 N. 2

MAIO-AGO 2017

ISSN 2317-6172

Recebido: 11.05 .2016

Aprovado: 10.05.2017

DOI: http://dx.doi.org/10.1590/2317-6172201725

1 Universidade Federal da Bahia Salvador - BA - Brasil

2 Universidade Federal da Bahia Salvador - BA - Brasil

\section{A medida de segurança na contramão da Lei de Reforma Psiquiátrica: sobre a dificuldade de garantia do direito à liberdade a pacientes judiciários}

THE DISTANCE BETWEEN DETENTION ORDER AND PSYCHIATRIC REFORM LAW: THE DIFFICULTY TO GUARANTEE TO LEGAL PATIENTS THE RIGHT TO FREEDOM

\author{
Alessandra Mascarenhas Prado ${ }^{1}$ Danilo Schindler ${ }^{2}$
}

\section{Resumo}

A medida de segurança, disciplinada pelo Código Penal brasileiro e pela Lei de Execução Penal, segue a lógica da internação como regra, em descompasso com o modelo assistencial em saúde mental disciplinado pela Lei de Reforma Psiquiátrica. Faz-se necessário refletir sobre essa intervenção e consequências em relação aos pacientes dos Hospitais de Custódia e Tratamento Psiquiátrico (HCTP). Assim, a pesquisa realizada objetivou identificar as dificuldades existentes para a desinternação de pacientes do HCTP/Bahia. Para tanto, mediante estudos descritivos e exploratórios, foi realizada pesquisa quantitativa e qualitativa a respeito dos efeitos da medida de segurança executada à luz da legislação penal vigente no HCTP/Bahia. Concluiu-se, por fim, que se faz urgente a revisão do modelo atual de medida de segurança, por dificultar a reintegração do ex-paciente do HCTP à vida em liberdade, e a necessidade de adequação do tratamento legal do infrator com transtorno mental à política de saúde mental traçada na Lei de Reforma Psiquiátrica.

\section{Palavras-chave}

Medida de segurança; reforma psiquiátrica; hospital de custódia; desinternação.

\section{Abstract}

The Criminal Code and the Criminal Execution Law prescribe the compulsory hospitalization, following the logic of internment as a rule, in disagreement with the model of attention in mental health disciplined by the Psychiatric Reform Act. It is necessary to reflect upon this intervention and consequences in relation to the patients of the Custody and Psychiatric Treatment Hospitals (HCTP). Thus, the research conducted aimed to identify the existing difficulties for social reintegration of HCTP/Bahia patients. In order to do so, through exploratory and descriptive studies, a quantitative and qualitative research was executed regarding the effects of the compulsory hospitalization implemented in accordance with the criminal legislation at HCTP/Bahia. It was concluded how urgent is the revision of the current model of criminal law intervention, due to the difficulties to guarantee patients freedom and their reintegration, and the need to adapt the legal treatment of the mentally ill persons to the mental health policy outlined in the Psychiatric Reform Law.

\section{Keywords}

Compulsory hospitalization; psychiatric reform; custody and psychiatric hospital. 


\section{INTRODUÇÃO}

A medida de segurança, conforme disciplinada pela legislação penal brasileira, representa a intervenção estatal na liberdade do indivíduo inimputável em razão de doença mental, que cometeu fato típico e antijurídico, à qual se atribui a função de tratamento, visando preservar a sociedade do perigo que o indivíduo representa.

Atualmente, conforme determina o Código Penal (art. 26), a medida de segurança aplica-se, em regra, aos inimputáveis que, em razão de doença mental, eram ao tempo do crime incapazes de entender e de se manifestar de acordo com seu entendimento; ou às pessoas que, em razão de um retardo mental ou desenvolvimento mental incompleto não eram ao tempo do crime inteiramente capazes de entender o caráter ilícito do seu ato ou de se manifestarem de acordo com esse entendimento (BRASIL, 1940). ${ }^{1}$

Com base na análise da legislação penal, especificamente, do art. 97 do Código Penal, considerando as espécies de medida de segurança previstas - internação e tratamento ambulatorial -, verifica-se que a primeira é aquela que, em regra, deve ser aplicada pelo juiz, ao passo que o tratamento ambulatorial deve ser exceção. Ou seja, o juiz só poderá determinar o tratamento extra-hospitalar se o fato previsto como crime for punível com detenção.

No tocante aos fundamentos que a legitimam, enquanto a pena está pautada no conceito de culpabilidade, a justificativa para a adoção da medida de segurança é a periculosidade presumida, fruto da influência da Escola Positiva (BRUNO, 1977), o que merece ser questionado uma vez que as ciências da saúde, como a Psiquiatria, fazem novas descobertas e promovem avanços no conhecimento e no tratamento das doenças mentais (BARROS-BRISSET, 2011; MARCHEWKA, 2004; GRACIA MARTÍN, 2007; PERES; NERY FILHO, 2002).

Verifica-se, ademais, que as novas perspectivas de tratamento - de medicalização e outras terapias utilizadas - acarretaram, no âmbito das Ciências da Saúde, uma mudança de perspectiva também no que diz respeito às políticas públicas que, por muito tempo, valorizaram a internação da pessoa com transtornos mentais (JACOBINA, 2008; TENÓRIO, 2002).

No Brasil, seguindo influência do movimento da luta antimanicomial ocorrido na Itália, liderado por Franco Basaglia, foi promulgada a Lei n. 10.216/2001, denominada Lei de Reforma Psiquiátrica, que dispõe sobre a proteção e os direitos das pessoas portadoras de transtornos mentais e redireciona o modelo assistencial em saúde mental. Trata-se

1 Ainda que não seja objeto deste artigo, cumpre mencionar que o Código de Processo Penal (art. 319) prevê medida que se assemelha à medida de segurança, que pode ser adotada ao longo do processo, isto é, a internação detentiva, prevista como medida cautelar diversa da prisão, aplicável nas hipóteses de crimes praticados com violência ou grave ameaça, quando os peritos concluírem ser o réu inimputável ou semi-imputável (BRASIL, 1941). 
de reconhecer a pessoa com transtorno mental como sujeito de direitos, do direito a um tratamento não institucionalizador e violento. ${ }^{2}$

Dessa forma, a medida de segurança precisa ser repensada à luz da reforma psiquiátrica, que se coloca como um contraponto ao discurso e à práxis da hospitalização, que, na seara criminal, tem sua base legal no art. 97 do Código Penal.

É importante, portanto, refletir sobre as características da medida de segurança cumprida em um Hospital de Custódia e Tratamento Psiquiátrico, que a legislação penal formalmente ainda legitima como busca do ideal de defesa social contra ato ilícito cometido pelo louco infrator, para que se possa analisar a distância que a separa da aplicação da Lei de Reforma Psiquiátrica, e o conflito existente entre essa prática encarceradora e a garantia de direitos das pessoas com transtorno mental.

Este artigo, então, objetiva examinar as dificuldades encontradas para a desinternação de pacientes do Hospital de Custódia e Tratamento Psiquiátrico da Bahia (HCTP/ BA), e assim verificar a importância da harmonização da legislação penal com a Lei de Reforma Psiquiátrica para garantia de direitos da pessoa com transtornos mentais que pratica conduta considerada crime.

Em um primeiro momento, realizou-se um estudo descritivo, sob uma perspectiva crítica, consistente em revisão bibliográfica e análise da legislação e de decisões dos tribunais relacionadas à disciplina legal da medida de segurança e da desinternação, como etapa em que deve se efetivar a reinserção social do paciente judiciário.

Em um segundo momento, foram executados o levantamento e a análise de documentos relacionados a pacientes do HCTP/BA que se encontravam em processo de desinternação, com o intuito de identificar as consequências da aplicação da medida de segurança nos moldes previstos na legislação penal e seu contraponto com o disposto na Lei n. 10.216/2001.

Nesse particular, analisaram-se 17 casos de pacientes judiciários do HCTP/BA, que se encontram na situação de abandono sociofamiliar. Foram, então, avaliadas as decisões judiciais de desinternação, como também as seguintes variáveis em relação aos pacientes e à sua situação sociojurídica: gênero; data de admissão no hospital; vínculos sociais; e medidas adotadas para viabilizar a desinternação.

Os resultados da pesquisa são analisados ao final do trabalho, confirmando-se a hipótese de que a execução da medida de segurança, nos moldes previstos na legislação penal,

2 A exposição de motivos do Projeto de Lei n. 3.657/89, apresentado pelo Deputado Paulo Delgado, que deu origem ao referido diploma legal, concluía: "A questão psiquiátrica é complexa, por suas interfaces com a Justiça e o Direito, com a cultura, com a filosofia, com a liberdade. [...] O que ela [lei] pretende é melhorar - da única forma possível - o atendimento psiquiátrico à população que depende do Estado para cuidar de sua saúde, e proteger em parte os direitos civis daqueles que, por serem loucos ou doentes mentais, não deixaram de ser cidadãos” (BRASIL, 1989). 
dificulta a garantia do direito à liberdade do paciente a ela submetido, necessitando de revisão com base no que dispõe a Lei de Reforma Psiquiátrica.

\section{i A medida de segurança na perspectiva do Código Penal brasileiro}

No Brasil, foi no Código Penal de 1940, com forte influência do Código Rocco, que a internação do louco infrator em um Hospital de Custódia e Tratamento foi reconhecida como medida de natureza jurídico-penal a ser imposta quando o indivíduo, ao praticar conduta tipificada como crime, revelasse periculosidade.

Nesse primeiro momento, a medida de segurança foi adotada para os inimputáveis em razão de doença mental, mas também àqueles que, embora imputáveis, fossem considerados perigosos, conforme o disposto no art. 77. O sistema do duplo binário, que permitia a aplicação de pena seguida da execução de uma medida de segurança, vigeu no Brasil até meados da década de 1980, quando foi alterada a Parte Geral do Código Penal.

No caso do indivíduo que, "[...] por doença mental ou desenvolvimento mental incompleto ou retardado, era, ao tempo da ação ou da omissão, inteiramente incapaz de entender o caráter criminoso do fato ou de determinar-se de acordo com esse entendimento" (art. 22) (BRASIL, 1940), o Código previa a aplicação de uma medida de segurança, tendo como pressuposto a prática da conduta prevista como crime e a periculosidade do agente (art. 76). E dispunha expressamente que tais indivíduos presumiam-se perigosos (art. 78).

Entretanto, por influência da Escola Sociológica ou Político-Criminal e da Terceira Escola Italiana, a medida de segurança passou a ser adotada como reação ao ato ilícito cometido pelo inimputável em razão de doença metal (GRACIA MARTÍN, 2007, p. 42), o que deu ensejo à adoção do denominado sistema vicariante. No Brasil, essa mudança de orientação ocorreu por meio da Lei n. 7.209/84, ainda em vigor, que reformou a Parte Geral do Código Penal e estabeleceu um novo sistema para aplicação das medidas de segurança.

Isso implicou a restrição da aplicação da medida de segurança ao inimputável que, em razão de "doença mental ou desenvolvimento mental incompleto ou retardado, era, ao tempo da ação ou da omissão, inteiramente incapaz de entender o caráter ilícito do fato ou de determinar-se de acordo com esse entendimento" (BRASIL, 1984); e aos indivíduos aos quais, em virtude de perturbação de saúde mental ou por desenvolvimento mental incompleto ou retardado não eram inteiramente capazes de entender o caráter ilícito do fato ou de determinar-se de acordo com esse entendimento, o juiz decidisse ser mais adequada a aplicação da medida de segurança, em substituição à pena (art. 26).

Manteve-se inalterada a definição de quem pode ser considerado inimputável em razão de doença mental (art. 26, caput), bem como a aplicação compulsória da medida de segurança.

Embora não haja mais referência expressa à presunção de periculosidade, esta não deixou de existir, estando implicitamente contida nas disposições dos referidos artigos. 
Além disso, o Código prevê que a medida será executada por tempo indeterminado (art. $97, \S 1^{\circ}$ ), dependendo da cessação da periculosidade, verificada por perícia médica.

\section{I FUndAMENTO: A PERICULOSIDADE (PRESUMIDA)}

A medida de segurança tem como fundamento básico a periculosidade do agente revelada no cometimento de ilícitos penais. Está apoiada no ideal de realização de defesa social, traduzindo-se como uma faceta do jus puniendi, com o fim de afastar pessoas perigosas do convívio social.

Aníbal Bruno (1977, p. 257) atenta que: "na doutrina, a instituição da medida de segurança resultou de dois movimentos que se manifestaram no Direito Penal nas últimas décadas" - diante do aumento criminalidade, para fins práticos de segurança, buscaram-se novos rumos - "defesa social era um dos termos do problema", intimidação e correção, a solução apresentada.

Ademais, para além da construção formal de crime, proposta pela Escola Clássica, a criminologia acentuava outros traços, "o homem com sua carga hereditária e as suas deformações criadas pela vida, esse homem que se extraviara da norma e em quem possivelmente existiam condições que o levariam novamente a delinqüir, [...] a sua condição, que os tornava inimigos potenciais da sociedade, foi chamada perigosidade criminal” (BRUNO, 1977, p. 257).

A partir do desenvolvimento da ideia de periculosidade ou perigosidade, o louco pôde também ser alcançado por medidas de natureza penal, pois, ao praticar um ilícito penal, se revelaria perigoso e, portanto, merecedor de um tratamento que prevenisse a prática de outros delitos. A teoria do estado perigoso, portanto, serviu e ainda serve de base para justificar a aplicação de medidas de segurança.

Entretanto, merece crítica o fundamento da periculosidade, que legitima a imposição da medida de segurança. De forma resumida, o que se entende por periculosidade é o risco que o indivíduo representa para a sociedade, presumido pelo fato de ele não ter condições de entender o caráter ilícito da conduta ou de se posicionar de acordo com esse entendimento, uma vez que se encontra afetado por uma doença mental no momento da ação o que se comprova por meio de um exame pericial.

Gracia Martín (2007, p. 52-53) esclarece que, se o fundamento das medidas de segurança é exclusivamente a perigosidade criminal, esta é que deve ser o conteúdo do "suposto de fato" que servirá para determinar e proporcionar a consequência jurídica (a medida). A partir daí atenta que o crime praticado pelo indivíduo deve ser considerado apenas um "sintoma revelador" de sua perigosidade, mas que esta não pode radicar no fato prévio em si. No entanto, destaca o referido autor que a exigência de anterior cometimento de um fato típico e antijurídico é, como diz Romeo Casabona (apud GRACIA MARTÍN, 2007, p. 53), "uma garantia para a segurança jurídica, ao contribuir para a diminuição de fatores de incerteza no prognóstico da perigosidade (nulla periculositas sine crimen), e para o próprio indivíduo, que não se verá submetido a um processo se não cometeu um delito”. 
O que ocorre atualmente é que o conceito de periculosidade não está definido no sistema normativo. A lei presume a periculosidade do infrator acometido por doença mental e ao Poder Judiciário é dado, mediante o exame médico-pericial, o atestado de que o indivíduo é perigoso para o convívio social - afinal, conforme criticam Antônio Nery Filho e Maria Fernanda Tourinho Peres (2002, p. 352-353), "a periculosidade é um risco e, por isso, uma incerteza que se expressará, talvez, num futuro também incerto”.

$\mathrm{O}$ exame que verifica a integridade mental e, consequentemente, a periculosidade do infrator se dá por meio de um incidente processual conhecido como incidente de insanidade; é realizado por psiquiatras, e será considerado pelo juiz para determinação da inimputabilidade do indivíduo e consequente imposição da medida de segurança.

Na perspectiva adotada por Gracia Martín (2007, p. 57, tradução nossa):

[...] o estudo das características típicas da personalidade do sujeito é muito importante, pois serão um indício de que sua possível perigosidade radica em componentes mais ou menos permanentes da personalidade, e não no delito concreto cometido. Certamente haverá que examinar outros fatores, como os biológicos, os ambientais etc.

Portanto, é preciso cuidar para que não se relacione a medida estritamente ao fato, sem a consideração da pessoa, pois, presumida a periculosidade com base em critérios objetivos, restariam desrespeitados o princípio da necessidade e da individualização da medida de segurança.

Atenta-se, porém, que a avaliação da insanidade (que é objeto do referido exame) não se confunde com a análise da perigosidade do sujeito: a primeira diz respeito à verificação da existência e da manifestação da doença mental no momento do fato, e se esta afastou a capacidade de entendimento e de vontade, enquanto a verificação da perigosidade deveria passar pela avaliação do risco que o indivíduo representa para o grupo social - o que não ocorre.

\section{I.2 A INTERNAÇÃo COMO REGRA E A CESSAÇÃo DA PERICULOSIDADE COMO SEU TERMO FINAL}

A partir da análise da legislação penal, especificamente, do art. 97 do Código Penal, considerando as espécies de medida de segurança previstas - internação e tratamento ambulatorial -, verifica-se que a primeira é aquela que, em regra, deve ser aplicada pelo juiz, enquanto o tratamento ambulatorial deve ser exceção, isto é, o juiz poderá determinar o tratamento extra-hospitalar apenas se o fato previsto como crime for punível com detenção.

O referido dispositivo legal torna legítima, na prática jurídica, a cultura do encarceramento para solução de problemas relacionados ao cometimento de atos ilícitos, mesmo por aqueles que sofrem de transtornos mentais. Ao mesmo tempo, reforça a exclusão social dessas pessoas, porque, assim como a pena privativa de liberdade, a internação compulsória em instituições totais não favorece mudanças positivas em relação ao indivíduo nem 
em relação ao contexto que o rodeia, mas acarreta um processo de “desculturação" (BARATTA, 2002, p. 183), de perda da identidade, de "desadaptação às condições necessárias para a vida em liberdade” (GOFFMAN, 1974, p. 11), por exemplo.

Percebe-se que o critério determinante para definir o tipo de medida de segurança nunca foi a necessidade do doente mental, e sim a gravidade do delito, seguindo a mesma proporcionalidade que deveria reger a previsão e aplicação da pena. Assim, aproximam-se os dois institutos, ignorando a necessidade de se verificar, no caso concreto, qual seria o tratamento adequado para o controle do transtorno mental.

Já no outro extremo - extinção da medida de segurança -, encontra-se o exame de cessação de periculosidade, que legitima a saída dos pacientes do Hospital de Custódia, considerado, então, o contraponto ao exame realizado no incidente de insanidade solicitado na fase de instrução processual penal.

O exame de cessação, em regra, será realizado depois de transcorrido o prazo que varia de um a três anos, de acordo com o que foi fixado pelo juiz na sentença, sob a égide do argumento da periculosidade do agente. Enquanto a periculosidade do agente não cessa, mantém-se a execução da medida de segurança, o que pode resultar na permanência de pacientes por décadas na instituição. Esse caráter restritivo da medida, sem falar na falta de infraestrutura adequada e de pessoal nessas unidades, resulta na privação de outros direitos durante longo período da vida do paciente.

Há que se destacar também que a duração indeterminada da medida de segurança, enquanto a periculosidade não cessar, é evidentemente inconstitucional, conforme o inciso XLVII do art. $5^{\circ}$ da Constituição Federal de 1988, que veda expressamente a aplicação de sanções penais de caráter perpétuo e cruéis, o que torna a desinternação, após determinado tempo de aplicação da medida de segurança, um direito do paciente e um dever do Estado.

No âmbito do Poder Judiciário, destacam-se, nesse sentido, manifestações do Supremo Tribunal Federal (STF), que entende que o limite da duração da medida de segurança é de 30 anos, conforme disciplina o art. 75 do Código Penal, em relação à pena; e do Superior Tribunal de Justiça (STJ), que é mais favorável, por compreender que o limite é o máximo da pena prevista em abstrato para o respectivo crime.

MEDIDA DE SEGURANÇA - PROJEÇÃO NO TEMPO - LIMITE. A interpretação sistemática e teleológica dos artigos 75, 97 e 183, os dois primeiros do Código Penal e o último da Lei de Execuções Penais, deve fazer-se considerada a garantia constitucional abolidora das prisões perpétuas. A medida de segurança fica jungida ao período máximo de trinta anos. [STF] (BRASIL, 2005)

Súmula 527. O tempo de duração da medida de segurança não deve ultrapassar o limite máximo da pena abstratamente cominada ao delito praticado. [STJ] (BRASIL, 2015) 
Já o Poder Executivo, por meio dos últimos sete Decretos (números 6.706/2008; 7.046/2009; 7.420/2010; 7.648/2011;7.873/2012;8.172/2013; e 8.380/2014), concede indulto aos cumpridores de medida de segurança que:

[...] independentemente da cessação de periculosidade, tenham suportado privação da liberdade, internação ou tratamento ambulatorial por período igual ou superior ao máximo da pena cominada à infração penal correspondente à conduta praticada. (BRASIL, 2014a)

Necessita, agora, o Poder Legislativo acompanhar tais entendimentos e delimitar o tempo da medida de segurança, para garantia da liberdade do inimputável em razão de doença mental.

\section{3 AusênCIA de PRevisão legal da DeSinternação PROGReSSiva}

A despeito de a medida de segurança ter duração indeterminada e da grande possibilidade de institucionalização do seu cumpridor, não há previsão legal na legislação penal sobre a adoção de um programa de desinternação progressiva, diversamente do que ocorre com as penas privativas de liberdade, que são executadas com base em um sistema progressivo (regime fechado, regime semiaberto e regime aberto de cumprimento da pena).

A instituição que comumente custodia os infratores classificados como inimputáveis em razão de doença mental é denominada Hospital de Custódia e Tratamento Psiquiátrico. É nessa instituição que se executa a medida de segurança de internação, pela qual são excluídas da convivência social essas pessoas, sob a presunção de representarem perigo à sociedade.

Conforme dispõe a Lei de Execução Penal (Lei n. 7.210/84), o Hospital de Custódia faz parte do sistema prisional. Porém há que se considerar que, embora seja uma unidade prisional, se é local para tratamento, para "fazer cessar a periculosidade" (o que pode se inferir a contrário senso do que dispõe a legislação penal), deveria ser principalmente uma unidade de saúde mental e, como tal, deveria estar integrada às redes de cuidados do Sistema Único de Saúde (SUS) e do Sistema Único de Assistência Social (SUAS).

Nesse sentido, a Portaria n. 001 / 2014, que institui a Política Nacional de Atenção Integral à Saúde das Pessoas Privadas de Liberdade no Sistema Prisional (PNAISP), no âmbito do SUS, na mesma esteira da Portaria (MJ/MS) n. 1.777/2003, visou "ampliar as ações de saúde do Sistema Único de Saúde (SUS) para a população privada de liberdade, fazendo com que cada unidade básica de saúde prisional passasse a ser visualizada como ponto de atenção da Rede de Atenção à Saúde” (BRASIL, 2016).

São também de grande relevância para o redirecionamento dos modelos de assistência à pessoa com transtorno mental cumpridora de medida de segurança as Portarias (MS/GM) n. 94/2014 e n. 95/2014. A primeira institui o Serviço de Avaliação e Acompanhamento de medidas terapêuticas aplicáveis à pessoa com transtorno mental em conflito com a lei, no âmbito do SUS; e a segunda dispõe sobre o financiamento do serviço de avaliação e 
acompanhamento às medidas terapêuticas aplicáveis ao paciente judiciário, no âmbito do SUS. Entre as atribuições da Equipe de Avaliação e Acompanhamento (EAP), destaca-se o acompanhamento da execução da medida terapêutica. A EAP funciona como "dispositivo conector entre os órgãos de Justiça, as equipes da PNAISP e programas e serviços sociais e de direitos de cidadania" (art. 4º , V, da Portaria n. 94/2014) (BRASIL, 2014b). A efetividade de tais portarias, entretanto, depende de adesão dos governos nas esferas estaduais e municipais.

No entanto, há a necessidade do reconhecimento por parte de todos que atuam no sistema penal - Poder Judiciário, Ministério Público, Administração Penitenciária, órgãos da Saúde - de que o tratamento-internação, adotado como regra, é danoso ao quadro clínico e psicossocial dos pacientes judiciários, afinal, é de fácil percepção que quando há a retirada do indivíduo do convívio social, cerceando sua liberdade com o objetivo de isolá-lo e medicá-lo de forma contínua, sem indicação médica, os danos psicológicos e clínicos apresentam-se inevitáveis.

\section{A medida de Segurança na contramão da Lei de Reforma Psiquiátrica}

A Declaração de Caracas (1990), para a América Latina e Caribe, resultante da Conferência Regional para Reestruturação da Assistência Psiquiátrica dentro dos Sistemas Locais de Saúde, aponta a necessidade de "revisão crítica do papel hegemônico e centralizador do hospital psiquiátrico na prestação de serviços” (ORGANIZAÇÃO PAN-AMERICANA DE SAÚDE, 1990), de alteração das legislações dos países, para que assegurem o respeito aos direitos humanos e civis dos doentes mentais e promovam "a organização de serviços comunitários de saúde mental que garantam seu cumprimento" (ORGANIZAÇÃO PAN-AMERICANA DE SAÚDE, 1990).

Como contraponto ao modelo que tem como centro a internação em Hospital Psiquiátrico, a reforma psiquiátrica, movimento que tomou força a partir da década de 1970 no Brasil e culminou com a promulgação da Lei n. 10.216/2001, trouxe inovações no que diz respeito à política pública de saúde mental que deve ser adotada em todo o país.

A Lei de Reforma Psiquiátrica estabelece como regra, no que concerne à forma de tratamento, o atendimento em liberdade e a utilização de recursos extra-hospitalares $\left(\operatorname{art} .4^{\circ}\right.$ ); além disso, o art. $6^{\circ}$ dispõe: “a internação psiquiátrica somente será realizada mediante laudo médico circunstanciado que caracterize os seus motivos” (BRASIL, 2001).

As bases da reforma psiquiátrica representam a negação do quanto disposto na legislação penal. Enquanto a medida de segurança é utilizada, em regra, na modalidade de internação, no intuito de tratar e retribuir condutas ilícitas, a reforma surge para percorrer o caminho inverso, desinternar para reabilitar e garantir cidadania à pessoa com transtorno mental.

A necessidade de adequação da imposição e da execução da medida de segurança às diretrizes da Lei n. 10.216/2001 é apontada pelo Conselho Nacional de Política Criminal e 
Penitenciária (CNPCP), por meio da Resolução n. 5/2004. Nesse documento, o CNPCP estabelece diretrizes para o cumprimento das medidas de segurança, tendo como objetivo adequá-las “aos princípios do SUS e às diretrizes previstas na Lei n. 10.216/2001”. E por meio da Resolução n. 04/2010, em seu art. 2º , CNPCP dispõe, por exemplo, que:

[...] a abordagem à pessoa com doença mental na condição de autor do fato, réu ou sentenciado em processo criminal, deve ser objeto de atendimento por programa específico de atenção destinado a acompanhar o paciente judiciário nas diversas fases processuais, mediando as relações entre o Poder Judiciário e o Poder Executivo, visando à promoção da individualização da aplicação das penas e medidas de segurança e no encaminhamento das questões de execução penal dos pacientes judiciários. (CONSELHO NACIONAL DE POLÍTICA CRIMINAL E PENITENCIÁRIA, 2010)

Também o Conselho Nacional de Justiça (CNJ), por meio da Resolução n. 113/2010, que trata do procedimento relativo à execução de pena privativa de liberdade e de medida de segurança, dispõe (no art. 17) que “o juiz competente para a execução da medida de segurança, sempre que possível, buscará implementar políticas antimanicomiais, conforme sistemática da Lei n. 10.216, de 06 de abril de 2001" (CONSELHO NACIONAL DE JUSTIÇA, 2010).

O modelo de execução da medida de segurança no Brasil deve, portanto, ser baseado nos elementos norteadores da reforma psiquiátrica, quais sejam: crítica ao modelo hospitalocêntrico; desinstitucionalização; negação do caráter terapêutico do internamento como regra; e redirecionamento do modelo assistencial à saúde mental em serviços substitutivos em meio aberto.

A reestruturação da Rede de Atenção à Saúde Mental que faz parte do Sistema Único de Saúde (SUS) é fundamental para que haja viabilidade na associação do cumprimento de medida de segurança com os princípios da reforma psiquiátrica. O desafio não é apenas desinternar, mas também fortalecer essa rede para que possa acompanhar o egresso do Hospital de Custódia. O acompanhamento multidisciplinar (realizado por psiquiatras, psicólogos, terapeutas ocupacionais e assistentes sociais), que se dá numa estrutura desburocratizada e extrajudicial, é de grande importância para garantia de direitos à pessoa com transtornos mentais.

\section{I ReESTRUTURAÇÃo dA APLiCAÇÃo dA MEDida de SEGURANÇA: OS MOdelos do PAI-PJ} E DO PAILI

A necessidade de alteração da legislação penal para garantia da execução da política pública de saúde mental traçada pela Lei n. 10.216/2001 é urgente, mas não deve ocorrer a curto prazo. O Projeto do novo Código Penal brasileiro (Projeto de Lei no Senado n. 236/2012) contempla dispositivos que, em certa medida - ainda de maneira tímida -, refletem tais 
anseios $;^{3}$ porém, ainda se encontra em trâmite no Congresso Nacional, sem perspectiva de quando será finalmente aprovado. ${ }^{4}$ Enquanto a reforma da Lei de Execução Penal, proposta pelo Projeto de Lei do Senado n. 513/2013, direciona a execução da medida de segurança à autoridade de saúde competente, com inserção dos dados no Cadastro Nacional de Saúde (art. 171 do Projeto), no âmbito doutrinário, no entanto, a produção a respeito do tema ainda é tímida. ${ }^{\mathbf{5}}$

Entretanto, na prática, já é possível apontar soluções de reestruturação da aplicação da medida de segurança, com a criação de modelos integrados ao SUS, como é o caso do Programa de Atenção Integral ao Paciente Judiciário Portador de Sofrimento Mental (PAI-PJ) em Minas Gerais, e do Programa de Atenção Integral ao Louco Infrator (PAILI), no estado de Goiás. Esses programas redimensionam a aplicação e a execução da medida de segurança, visando garantir, em regra, direitos, entre eles a liberdade da pessoa com transtornos mentais.

O Tribunal de Justiça de Minas Gerais criou, em 2001, por meio da Portaria-Conjunta n. 25, o Programa de Atenção Integral ao Portador de Sofrimento Mental Infrator (PAI-PJ), com o fim de "realizar a mediação entre o tratamento e o processo jurídico, até o tempo da inserção social das pessoas” (BARROS-BRISSET, 2010, p. 26). Assim, o PAI-PJ, além de auxiliar "a autoridade judicial na individualização da aplicação e execução das medidas de segurança”, viabiliza "a acessibilidade aos direitos fundamentais e sociais previstos na Constituição da República, almejando ampliar as respostas e a produção do laço social dessas pessoas" (BARROS-BRISSET, 2010, p. 28).

3 "Espécies de medidas de segurança

Art. 94. São medidas de segurança: I - internação compulsória em estabelecimento adequado; II sujeição a tratamento ambulatorial.

$\S 1^{\circ} \mathrm{Na}$ aplicação das medidas de segurança deverão ser observados os direitos das pessoas com deficiência, inclusive os previstos na legislação específica.

$\S 2^{\circ}$ Extinta a punibilidade, não se impõe medida de segurança, nem subsiste a que tenha sido imposta. Art. 95. O prazo mínimo da medida de segurança deverá ser de um a três anos.

$\S 1^{\circ}$ Cumprido o prazo mínimo, a medida de segurança perdurará enquanto não for averiguada, mediante perícia médica, a cessação da periculosidade, desde que não ultrapasse o limite máximo: I da pena cominada ao fato criminoso praticado; ou II - de trinta anos, nos fatos criminosos praticados com violência ou grave ameaça à pessoa, salvo se a infração for de menor potencial ofensivo.

$\S 2^{\circ}$ Atingido o limite máximo a que se refere o $\S 1^{\circ}$, poderá o Ministério Público ou o responsável legal pela pessoa requerer, no juízo cível, o prosseguimento da internação.” (BRASIL, 2012)

4 O Projeto está com a Comissão de Constituição, Justiça e Cidadania (Secretaria de Apoio à Comissão de Constituição, Justiça e Cidadania) do Senado desde 13 de outubro de 2015, aguardando designação do relator (BRASIL, 2012).

5 Vide: Jacobina (2003); Correia (2007, p. 20-21); Marchewka (2004); e Queiroz (2010, p. 440-441). 
Em resumo, o PAI-PJ é executado da seguinte forma: após determinação do juiz, a equipe de psicologia realiza uma avaliação do caso e imediatamente o acompanha até a rede pública de saúde visando a construção de um projeto clínico - que pode resultar em internação hospitalar ou no centro de referência em saúde mental (em caso de crise) ou na adoção de medidas extra-hospitalares, a exemplo do encaminhamento para serviços de hospital-dia, centros de saúde, oficinas de trabalho terapêutico, centros de convivência, orientação e tratamento odontológicos ou assistência social. O Serviço Social participa a partir da realização de estudo do caso e orientação para garantia dos benefícios que o Estado assegura a esses cidadãos. Também a família recebe orientação, acolhimento e assistência psicológica individual ou em grupo.

O outro modelo existente é o Programa de Atenção Integral ao Louco Infrator (PAILI), criado em 2006, por meio do qual se dá a execução das medidas de segurança no estado de Goiás. O programa tem por fundamento os princípios que regem a Lei n. 10.216/2001, e está vinculado à Secretaria da Saúde do Estado.

A equipe do Programa é formada por advogado, assistentes sociais, psicólogos e assistente administrativo, com previsão para contratação de psiquiatra, e tem a responsabilidade de, segundo a Portaria n. 019/2006-GAB/SES,

[...] fazer a mediação com o juiz e o sistema penitenciário, com a rede de atenção em saúde mental e, neste particular, coloca a pessoa submetida à medida de segurança no ambiente universal e democrático do Sistema Único de Saúde, sem distinção de outros pacientes, o que favorece sobremaneira a almejada inclusão à família e à sociedade. (GOIÁs, 2006)

Atenta-se ainda para o fato de que a aplicação da medida de segurança depende ainda de uma sentença judicial, e a sua execução será acompanhada pelo juízo da execução penal. Entretanto, a determinação da espécie da medida de segurança a ser aplicada e a indicação da terapia a ser utilizada fica a critério do médico, com a colaboração da equipe psicossocial.

Verifica-se, assim, a existência no Brasil de experiências pioneiras de aplicação da Lei de Reforma Psiquiátrica no âmbito penal, alterando completamente tanto a determinação quanto a execução da medida de segurança, tratando-a principalmente como uma questão de saúde pública, e não apenas de controle social.

$\mathrm{O}$ atendimento individualizado e direcionado à inserção dos doentes mentais na sociedade é apontado como um caminho importante no resgate desses indivíduos como sujeitos de direito. Fernando Tenório ressalta:

[...] a importância analítica de se localizar a cidadania como valor fundante e organizador deste processo está em que a reforma é sobretudo um campo heterogêneo, que abarca a clínica, a política, o social, o cultural e as relações com o jurídico, e é obra de atores muito diferentes entre si. (TENÓRIO, 2002, p. 28) 
Esse novo sistema de execução das medidas de segurança necessita, porém, pelas características dos dois programas antes referidos, do fortalecimento da rede de saúde e apoio psicossocial no âmbito dos estados-membros e dos municípios, e da sensibilização daqueles que atuam na área jurídica - juízes, defensores públicos, promotores e advogados -, para que assumam o compromisso de colocar em prática o que estabelece a Lei de Reforma Psiquiátrica.

Como resultado da pesquisa descritiva, concluímos pelo descompasso existente entre a legislação penal e a Lei de Reforma Psiquiátrica. Então, partindo-se da hipótese de que o modelo de intervenção penal no tocante à pessoa com transtorno mental implica ofensa a direitos fundamentais, como saúde e liberdade, enquanto o modelo da Lei n. 10.216/2001 visa garantir direitos a tais pessoas, decidimos realizar, de forma complementar, pesquisa qualitativa a respeito dos efeitos da medida de segurança executada à luz da legislação penal vigente no HCTP/BA.

\section{Pacientes Judiciários institucionalizados e A dificuldade de Retorno À LIBERDADE: A REALIDADE DE PACIENTES DO HCTP/BA}

Nesta segunda etapa, visando a um aprofundamento na análise de como os agentes envolvidos na execução penal aplicam a legislação penal e as repercussões para os cumpridores das medidas de segurança, a pesquisa constituiu um estudo exploratório da situação em que se encontravam os cumpridores da medida de segurança, mas com um recorte específico em relação àqueles que, liberados do cumprimento da medida de internação, ainda estavam custodiados na unidade prisional.

O levantamento de casos foi feito entre outubro de 2012 e março 2013 no próprio Hospital de Custódia e Tratamento Psiquiátrico (HCTP/BA), única unidade prisional dessa espécie no estado da Bahia. À época, havia no hospital 85 pessoas -12 mulheres e 73 homens - cumprindo medida de segurança, sendo 17 casos de pessoas institucionalizadas, impossibilitadas de exercer seu direito de ir e vir.

Assim, a pesquisa restringiu-se aos casos de pacientes do HCTP/BA, cumpridores de medida de segurança, com sentenças judiciais favoráveis à desinternação (17) - seja pela cessação da periculosidade (13), seja pela conversão do internamento compulsório em tratamento ambulatorial (4) -, e que não conseguiram ser desinternados por apresentarem problemas sociais, os quais serão detalhados adiante.

\section{I O RECORTE DA PESQUISA DOCUMENTAL}

Os propósitos da pesquisa exploratória foram: conhecer o perfil dos internos do HCT/BA e como ocorre o processo de desinternação dos pacientes do HCTP/BA, bem como analisar o conflito entre a efetivação do direito à liberdade e as dificuldades encontradas para concretização desse direito em relação aos indivíduos que, embora liberados pelo Poder Judiciário, ainda se encontravam no HCTP/BA. 
As fontes utilizadas para realização dessa parte da pesquisa foram documentos e dados disponibilizados para consulta pelo Hospital de Custódia e Tratamento Psiquiátrico - Bahia; sentenças e decisões da Vara de Execuções de Penas e Medidas Alternativas - TJ/BA; e acórdãos da Câmara Criminal do Tribunal de Justiça da Bahia. As informações colhidas foram ainda complementadas por informações prestadas por servidores do HCTP/BA.

A coleta de dados foi feita com o fim de traçar o perfil dos internos que aguardavam sua desinternação (gênero e naturalidade) e conhecer algumas circunstâncias relevantes que poderiam contribuir para aferir os efeitos da institucionalização dessas pessoas e as dificuldades de sua desinternação: existência de documentação; data da última admissão no HCTP; data do último laudo de cessação de periculosidade; família conhecida e outros vínculos sociais; data de desinternação; encaminhamento dado após desinternação; e motivo da não desinternação. Os dados foram analisados não apenas do ponto de vista quantitativo, mas principalmente do que seus conteúdos revelaram.

Em um levantamento de dados, foram selecionados os casos de cumpridores de medida de segurança de internação no HCTP/BA que, em 2013, com sentenças judiciais favoráveis à desinternação, e que, por diferentes razões, apresentavam problemas sociais prejudiciais à concretização do direito fundamental à liberdade. Foram encontradas 17 pessoas nessa situação.

Dos casos em análise, verificou-se que, do universo de 17 pacientes pesquisados, 15 são do sexo masculino e apenas dois são do sexo feminino, o que reproduz a mesma realidade dos cumpridores de penas privativas de liberdade: a maioria é composta de pessoas do sexo masculino.

Quanto à origem dos custodiados, 15 pacientes são do interior do estado da Bahia, um da capital e um de outro estado da Federação. ${ }^{6}$

\subsection{Entrada e saída: sobre a data de admissão no Hospital de Custódia e a data do} LAUDO DE CESSAÇÃO DE PERICULOSIDADE

Foi avaliada também a data da última admissão desses pacientes no Hospital de Custódia. Salienta-se a última admissão, pois todas as pessoas do universo pesquisado tiveram mais de uma entrada registrada na unidade.

Foi constatado, entre os casos pesquisados, que existem dois pacientes há mais de 30 anos na unidade e que, em razão de suas debilidades físicas e mentais, aliadas ao abandono

6 Deve ser objeto de outra pesquisa, posteriormente, a análise mais aprofundada sobre tais dados, relacionando-os a dados referentes à assistência prestada à população do município por meio do Centro de Referência de Assistência Social (CRAS), Centro de Atenção Psicossocial (CAPS), Residência Terapêutica (RT), entre outros, para verificar a hipótese de que nos municípios em que dispositivos de assistência social ou à saúde mental oferecem seus serviços, o número de pessoas sujeitas à medida de segurança, abandonadas sociais, seja menor. 
social, se encontram institucionalizados e necessitam de cuidados maiores por parte da instituição que os receba.

O reingresso na unidade prisional também é um importante fator a sugerir uma reflexão a respeito das razões para o cometimento de novos atos ilícitos. Essa reincidência se dá em virtude do alto nível de periculosidade que essas pessoas representam para a sociedade ou da gravidade de sua enfermidade, aliada ao abandono social que os coloca sem qualquer oportunidade de sobrevivência fora da estrutura da unidade prisional, contribuindo assim para seu retorno ao Hospital de Custódia?

É simplista a crença de que pessoas com transtornos mentais muitas vezes graves são perigosas apenas por causa de sua enfermidade. Há muitos outros fatores que não são levados em conta quando se trata de cometimento de novos atos considerados crimes após a desinternação.

Não é possível ignorar que a pessoa com transtorno mental sempre necessitará de acompanhamento médico, em maior ou menor grau - o que não significa internação, mas medicação e outras formas de terapia. O abandono social, a falta de meios de subsistência, a falta de estrutura física fora do hospital que os acolha e atenda suas necessidades são fatores que não podem ser esquecidos quando se trata da prática de novos ilícitos pós-desinternação. A periculosidade é uma justificativa engendrada pelo positivismo para tratar a saúde mental como questão de segurança pública e estabelecer uma política higienista dos comportamentos fora do padrão médio de conduta.

O tempo de cumprimento de medida de segurança é determinado em sentença condenatória pelo juiz que absolve o réu, mas aplica a medida de segurança, que variará de um a três anos, como dito anteriormente. Transcorrido esse prazo, terá de ser realizado exame de cessação de periculosidade para averiguação das condições médicas e psicossociais do paciente, no intuito da desinternação. Caso não tenha havido a cessação da periculosidade, o exame será realizado anualmente (art. 97, § $1^{\circ}$, do Código Penal).

Observa-se que, em virtude do desvio de função do HCTP - além dos cumpridores de medida de segurança, recebe também pessoas para realização do exame de insanidade, bem como presos provisórios e pessoas em outras situações sui generis (internações por ordem judicial sem que haja processo penal) - e da carência de pessoal, os exames deixam de ser realizados no tempo correto; o papel da Defensoria Pública, nesses casos, se mostra de extrema relevância na defesa dos interesses dos pacientes judiciários. Todos os casos analisados possuem registro de exame médico pericial (laudo de cessação de periculosidade) favorável à desinternação.

Dos 17 pacientes, quatro laudos não se referem à cessação de periculosidade, mas à substituição da internação por tratamento extra-hospitalar. Portanto, no tocante ao laudo de cessação, importam 13 casos.

Entre estes, dez deles realizaram os últimos exames com resultado favorável à desinternação entre 2009 e 2013. Dois ainda aguardavam por nova avaliação do juiz acerca da necessidade de novo exame; e um deles faleceu ao longo da realização da pesquisa - o que dificultou o acesso 
ao seu prontuário, pois este foi arquivado. Esses pacientes que aguardam avaliação do juiz sobre a necessidade de novo exame apresentavam grande debilidade em seu quadro clínico e remota perspectiva de desinternação por ausência de uma instituição que aceitasse recebê-los.

\subsection{Abandono social}

$\mathrm{Na}$ perspectiva dos vínculos sociais, esta pesquisa avaliou casos com problemas sociais graves, ou seja, com os vínculos familiares e sociais muito frágeis ou praticamente inexistentes. A problemática do desamparo social é uma das razões mais contundentes que justificam a ineficácia das desinternações judiciais sem o apoio familiar.

O cumpridor da medida de segurança que é desinternado sem o necessário apoio da família se torna um vulnerável social, afinal, acometido de enfermidade mental. Sua periculosidade é dada como cessada, mas as suas necessidades como doente não cessam, e, se não houver o acompanhamento necessário, a doença pode voltar a se manifestar. Nesse caso, se outra conduta ilícita for praticada, poderá voltar ao cumprimento de medida de segurança.

Entre os 17 casos de abandono social, o setor psicossocial não conseguiu localizar familiares de nove internos; e tem o contato de familiares de oito internos.

\section{3. i Abandono social total}

Entre os casos analisados, nove internos foram classificados como pacientes em situação de abandono social total, uma vez que os esforços empenhados pelos profissionais do setor psicossocial do Hospital de Custódia em encontrar os vínculos sociais desses pacientes foram infrutíferos. Deles não se conhece família, nem parentes, nem amigos.

\section{3·3.2 Família localizada, paciente abandonado}

Entre os outros oito pacientes que mantêm vínculos familiares conhecidos, identificou-se que, em dois casos, os familiares são tias distantes; em seis casos, há o registro de familiares do núcleo mais próximo (pai, mãe e/ou irmão/ã).

É interessante apontar que, entre os pacientes com vínculos familiares conhecidos, todos os casos exibem peculiaridades que reforçam o caráter estigmatizante e segregador do instituto da medida de segurança no ideário social.

A população carcerária do Hospital de Custódia é composta basicamente de pessoas com baixo poder aquisitivo, muitas delas beneficiárias de programas sociais do governo ou de auxílios previdenciários, como o Benefício de Prestação Continuada (BPC).

Em relação aos oito casos de famílias localizadas, em cinco deles, o setor psicossocial informa que os familiares alegam falta de condições financeiras para recebê-los de volta; e, em um caso, a família não quis mais receber o interno de volta após sua terceira reinternação no HCTP.

Nos oito casos que mantinham vínculos sociais, o fator renda foi a principal justificativa impeditiva para o acolhimento dos pacientes após a desinternação; porém, o que 
se verificou é que as famílias não desejam acolher seus familiares que cumpriram medida de segurança.

Em dois casos específicos, as famílias retinham os documentos de identificação dos pacientes e recebiam em seu nome benefício previdenciário a que o paciente fazia jus, não davam qualquer satisfação quanto à renda auferida e tampouco repassavam o dinheiro para as necessidades dos verdadeiros beneficiários.

Em outro caso analisado, pessoas da cidade natal do paciente fizeram um abaixo-assinado solicitando à Secretaria de Administração Penitenciária que o paciente não retornasse à cidade. O paciente do HCTP, além do preconceito que sofre em relação ao fato de ter transtorno mental, também sofre com o estigma de ter habitado uma unidade prisional.

Mais uma vez, se evidencia o caráter estigmatizante da medida de segurança, servindo a internação como forma de defesa social ou de isentar a família dos cuidados com a pessoa com transtorno mental.

No entanto, é preciso considerar que a família também necessita de assistência e acompanhamento para que possa lidar com a situação da pessoa com transtorno mental. As estruturas hospitalares muitas vezes dificultam essa aproximação, ao passo que a assistência extra-hospitalar pode favorecer esse duplo acompanhamento (paciente/família), pois mais próximo e acessível.

Maria Alice Ornellas Pereira atenta para as dificuldades vividas pelas famílias, normalmente carentes de informações e recursos financeiros:

[...] o peso do sofrer psíquico, de quem vive e sente a doença mental, também tem sua extensão na família. Esta, com raras exceções, recebe pouca atenção do sistema de saúde, não é chamada à participação, uma vez que a prática psiquiátrica “adota” ou tutela o doente, tirando-o do convívio social e familiar. Ao mesmo tempo, evidencia-se o entendimento do importante papel da família no processo de ressocialização e reabilitação do doente mental. Nesta perspectiva, à medida que cresce a proposta de uma assistência mais abrangente, aumenta a necessidade de eficiência do serviço de saúde no cumprimento de seu papel. Isto significa que o interesse e a solicitação podem ocorrer concomitantemente ao aumento da eficácia e competência do sistema. A construção desse modelo de assistência tem causado profundos efeitos na sociedade atual, pois implica mudança cultural da instituição, dos usuários, dos profissionais de saúde, da família e da comunidade. Dessa forma, não se visa somente tratar de uma doença, mas também à promoção da saúde mental, à adaptação do sujeito à sua realidade. Nesta proposta descronificam-se os atores envolvidos, uma vez que ela propicia, gradativamente, a ampliação da rede social e a co-divisão de responsabilidades inerentes à sociedade, a qual aumenta o encargo da família que será despertada para solicitações, reivindicações e aportes necessários para o convívio e o enfrentamento da doença mental. (PEREIRA, 2003, p. 72-73) 
Portanto, a importância de investimento na estruturação e manutenção dos centros de atendimento psicossocial, entre outros dispositivos de assistência social e saúde mental, é de grande relevância para assegurar o fortalecimento dos vínculos sociais e familiares da pessoa com transtorno mental.

\section{3•4 Ausência de documentação e garantia de direitos}

No tocante aos documentos de identificação dos pacientes, constatou-se que esse é um quesito que revela um dos principais entraves burocráticos à efetivação do direito à liberdade. Verifica-se que é uma prática comum o recebimento de pacientes, por determinação judicial, sem que estes apresentem documentação alguma. Na unidade, é feita a identificação criminal e, após esta etapa, inicia-se um longo caminho burocrático no intuito de identificar a real identidade dessas pessoas.

No universo pesquisado de 17 casos, oito necessitaram da intervenção dos profissionais do setor psicossocial do Hospital de Custódia, assim como dos profissionais da Defensoria Pública do Estado, num esforço conjunto de identificar esses pacientes, para resgatar sua identidade.

\subsection{Os "INEXISTENTES"}

Em quatro dos oito casos de pacientes com problemas de documentação, o contato com familiares viabilizou a solução; nos outros, foi necessário realizar identificação datiloscópica no intuito de buscar registros civis preexistentes. Desses, três pacientes necessitaram da abertura de Ação de Assentamento de Registro, por não ter sido encontrado indicativo de identificações anteriores, não constando notícias recentes sobre o andamento do respectivo processo. Diante da carência de pessoal, a Defensoria Pública não estava prestando atendimento constante no HCTP.

Pessoas inexistentes, sem conhecimento de sua origem; sem vínculos familiares; com codinomes, quem sabe; com idade incerta; anuladas; impossibilitadas de usufruir de seus direitos; vítimas de tantas carências, inclusive, de sua identidade. Parece ser o extremo da situação que Erving Goffman (1974, p. 29) denomina "mortificação do eu”, como efeito das instituições totais, quando o indivíduo é submetido a diferentes formas de indignidades, como "perder seu conjunto de identidade" ou sofrer a "violação da reserva de informação quanto ao eu".

Entre os prejuízos sofridos pela ausência de documentação, destacam-se a impossibilidade de recebimento de benefícios a que os pacientes têm direito, a exemplo do Benefício de Prestação Continuada (BPC), bem como a dificuldade de aceitação dessas pessoas em abrigos, residências terapêuticas ou estabelecimentos similares.

\subsection{As SENTENÇAS DE DESINTERNAÇÃO}

A pesquisa se deteve a analisar as sentenças de desinternação dos pacientes custodiados. No universo de 17 casos encontrados, verificou-se que dez pacientes já possuíam laudo de exame 
de cessação de periculosidade favorável à desinternação. É importante frisar que esses dez pacientes cumpriram integralmente o tempo da medida estipulado na sentença condenatória absolutória imprópria.

Quatro pacientes possuíam sentença favorável à conversão da medida de segurança internamento em medida tratamento ambulatorial; um paciente faleceu em julho de 2013 por causa de problemas cardíacos, o que dificultou o acesso a seu prontuário e informações; e outros dois aguardavam realização de novo exame de cessação, pois havia considerável lapso temporal desde o último exame.

Esses três últimos casos são situações de difícil desinternação em virtude das condições clínicas em que se encontram, o que acarreta a negativa de acolhimento em outros locais.

Nas sentenças e acórdãos analisados, não se constatou encaminhamento para o acompanhamento dos pacientes após a desinternação. O que se verificou, no entanto, foi que nas sentenças de conversão da medida de internamento em medida tratamento ambulatorial há disposições claras acerca das restrições de direitos e determinações sobre parâmetros comportamentais a que o ex-paciente judiciário deve se submeter.

Dessa maneira, é perceptível que o Poder Judiciário, numa atitude de zelo pela defesa social, amparado pela legislação penal vigente, impõe aos pacientes parâmetros comportamentais em que o doente não exerce completo domínio de sua enfermidade e suas formas de manifestação.

Além da restrição de direitos que foi usualmente encontrada nas sentenças de conversão de medida de internação em medida tratamento ambulatorial, como "não frequentar estabelecimentos comerciais de venda de bebida alcóolica nem fazer uso de bebida alcoólica ou outras substâncias congêneres", "submeter-se a tratamento no CAPS - Centro de Atenção Psicossocial”, existem também determinações como: "manter bom relacionamento com amigos, familiares e estranhos".

Em três das sentenças de desinternação, na extinção da medida de segurança por cessação da periculosidade, detalhou-se a responsabilidade do encaminhamento do paciente desinternado à Coordenação de Saúde Mental do município, para que esta alocasse o paciente em residência terapêutica.

$\mathrm{Na}$ pesquisa, constatou-se que, no interregno de outubro de 2012 a março de 2013, só foram efetivamente desinternados quatro dos 17 pacientes pesquisados, os quais foram transferidos para residências terapêuticas mantidas pela municipalidade, sob ingerência financeira do Sistema de Atenção à Saúde Básica. As residências terapêuticas fazem parte de um modelo de atenção à saúde como política pública, entretanto, são criticadas por conter traços e possibilidade de institucionalização dos moradores.

Os pacientes que saíram do HCTP foram encaminhados a casas de repouso e a uma residência terapêutica. Salienta-se mais uma vez que todos os casos desta pesquisa são de pessoas com problemas sociais graves, casos que são marcados pelo desamparo social; consequentemente a desinternação dessas pessoas se dá de maneira bem lenta, dependendo de 
providências de outros órgãos públicos - Secretarias Municipais de Saúde -, principalmente para a designação de uma estrutura de atenção à saúde mental que possa recebê-las.

Verifica-se, nas escutas feitas em reuniões e leituras dos prontuários que, além da carência de vagas, há resistência, por parte dos serviços públicos ofertados extramuros em receber os pacientes do Hospital de Custódia. Então, o lugar que lhes resta, mesmo após a declaração de cessação de sua periculosidade, é ali, escondidos, invisíveis, privados de sua liberdade.

\section{CONSIDERAÇÕES FINAIS}

A institucionalização representa a alienação dos pacientes custodiados, que se adaptam a uma vida cheia de regras e atividades predefinidas, que fazem parte da dinâmica do Hospital de Custódia. Nesses locais, os remédios, bem como a alimentação, são dados em hora certa, existem momentos definidos para acordar, para dormir, para tomar banho de sol, entre outras atividades.

Quando finalmente é verificada a cessação de sua periculosidade e há a possibilidade de concretização de seu direito fundamental de ir e vir, a liberdade esbarra em dificuldades concretas de readaptação a um mundo que é hostil às limitações da pessoa com doença mental, principalmente a que saiu do HCTP.

A medida de segurança não pode ser tratada apenas como assunto de segurança pública, de política criminal. É forçoso e imprescindível o reconhecimento dos pacientes judiciários como sujeitos de direito. Enquanto não houver ingerência de políticas públicas de saúde mental no instituto da medida de segurança, os pacientes judiciários continuarão a ser esquecidos, excluídos do convívio social.

A Lei de Reforma Psiquiátrica (Lei n. 10.216/2001) surge no cenário jurídico brasileiro como resultado do movimento de luta pelo reconhecimento dos direitos das pessoas com enfermidade mental e revela a necessidade de mudança da política criminal, para que se reconheçam às pessoas com transtornos mentais que cometeram um fato considerado crime os mesmos direitos que a lei prevê para todos os enfermos mentais. Dessa maneira, percebe-se que esta lei deve ser aplicada tanto no sistema de saúde comum não judicializado como no âmbito do sistema prisional.

As mudanças de política criminal, que a citada lei deve guiar, têm ocorrido de maneira muito vagarosa. A cultura do encarceramento do louco infrator ("lugar de louco é no hospício”) e a presunção da periculosidade ainda são pontos de partida para a disciplina e aplicação da medida de segurança, na maioria dos casos.

Com a análise dos 17 casos do HCTP/BA, foi possível verificar que a medida de segurança de internação, aplicada como regra, não respeita o direito da pessoa com transtorno mental às assistências médica e psicossocial adequadas, institucionaliza esse indivíduo e dificulta seu retorno ao convívio social, pois lhe retira a autonomia, acarreta um corte com os poucos vínculos sociais, a torna ainda mais esquecida pela sociedade e pelos órgãos públicos. 
A internação afasta mais ainda a família do indivíduo, dificultando sua reinserção social. Em relação aos dados coletados no HCTP/BA, constatou-se que a medida de segurança, embora em algum momento alcance a esperada cessação de periculosidade de pacientes, estigmatiza a pessoa portadora de transtorno mental que passa pelo HCTP, o que contribui para o afastamento ou a quebra do vínculo familiar; aumenta a dificuldade em se localizarem os familiares; e se eterniza quando o HCTP tem desvirtuado seu propósito, pois para não abandonar essas pessoas continua a abrigá-las até que possam encontrar pessoas ou instituições que as recebam.

Mesmo com a medida judicial de desinternação, a família por vezes deixa de acompanhar o tratamento do paciente ou não recebe assistência para lidar com o transtorno e suas consequências. Esses fatores, somados à dificuldade de acesso aos serviços de saúde em determinadas localidades, enfraquecem os laços ou dificultam sua retomada.

Em sentido oposto, o tratamento em meio aberto pode favorecer a manutenção dos vínculos familiares, mediante o acompanhamento, com menor dificuldade, não apenas da pessoa com transtorno mental, como também o de sua família, com menor grau de estigmatização e, assim, maior probabilidade de sucesso na inserção social desse indivíduo.

A exclusão social resultante da medida de segurança de internação prolonga-se mesmo após a declaração da cessação a periculosidade, não por desídia da administração do HCTP / BA em reconhecer essa situação jurídica, mas em razão do estigma que o paciente carrega e que resulta na dificuldade de ser aceito pela família, pela comunidade de origem ou por outras instituições, a exemplo de residências terapêuticas e abrigos.

A situação torna-se ainda mais complexa quando a pessoa não tem documentos de identificação, conforme revelaram quatro casos de pacientes que, com todos os esforços empenhados pela equipe psicossocial do HCTP, não puderam ser identificados. Tal situação implica a impossibilidade de recebimento de benefícios a que esses pacientes têm direito, a exemplo do Benefício de Prestação Continuada (BPC) e, consequentemente, a dificuldade de aceitação dessas pessoas em outros lugares.

Constatou-se, entre os casos pesquisados, a presença de dois pacientes internados há mais de 30 anos na unidade - sem identificação, sem familiares conhecidos - e que, em razão de sua debilidade física e mental, aliada ao abandono social, se encontram institucionalizados, necessitam de cuidados maiores e são alvo de um maior preconceito e dificuldade de inserção em outra instituição.

A pesquisa constata então a institucionalização de 17 pacientes que ainda aguardam vagas na rede pública de atenção à saúde para serem desinternados, apesar da decisão que determina o retorno ao convívio social extramuros, desvinculado do HCTP, e a dificuldade de se desvencilharem do estigma da periculosidade, reforçado por sua passagem e tempo de permanência em uma unidade prisional.

Assim, a revisão da legislação penal brasileira faz-se necessária e urgente, seguindo a lógica da política em saúde mental disciplinada pela Lei n. 11.216/2001, que determina 
o tratamento extra-hospitalar como regra, cabendo internação somente se laudo médico determinar a sua necessidade, bem como as experiências que se consolidam, nesse sentido, com o PAI-PJ e o PAILI, e as orientações constantes na Resolução CNPCP n. 05/2004 e nas Portarias (MS/GM) n. 94/2014 e n. 95/2014.

\section{REFERÊNCIAS}

BARATTA, Alessandro. Criminologia crítica e crítica ao direito penal. Introdução à sociologia do Direito Penal. Trad. Juarez Cirino dos Santos. Rio de Janeiro: Revan, 2002.

BARROS-BRISSET, Fernanda Otoni de. Por uma política de atenção integral ao louco infrator. Belo Horizonte: Tribunal de Justiça do Estado de Minas Gerais, 2010.

- Genealogia do conceito de periculosidade. Responsabilidades: Revista Interdisciplinar do Programa de Atenção Integral ao Paciente Judiciário - PAI-PJ. Belo Horizonte, p. 37-52, 2011.

BRASIL. Câmara dos Deputados. Projeto de Lei n. 3.657, de 1989. Dispõe sobre a extinção progressiva dos manicômios e sua substituição por outros recursos assistenciais e regulamenta a internação psiquiátrica compulsória. Diário do Congresso Nacional, Brasília, 29 set. 1989, Seção I, p. 10696. Disponível em: <http://imagem.camara.gov.br/Imagem/d/pdf/DCD29SET1989.pdf\#page=30>. Acesso em: 17 maio 2017.

Ministério da Saúde. Política Nacional de Atenção Integral à Saúde das Pessoas Privadas de Liberdade no Sistema Prisional (PNAISP). Brasília, 2016.

Ministério da Saúde. Portaria n. 94, de 14 de janeiro de 2014. Institui o serviço de avaliação e acompanhamento de medidas terapêuticas aplicáveis à pessoa com transtorno mental em conflito com a Lei, no âmbito do Sistema Único de Saúde (SUS). D.O.U. Brasília, 14 jan. 2014 b.

Presidência da República. Decreto-Lei n. 2.848, de 7 de dezembro de 1940. Código Penal. D.O.U. Rio de Janeiro, $31 \mathrm{dez} 1940$.

Presidência da República. Decreto-Lei n. 3.689, de 3 de outubro de 1941. Código de Processo Penal. D.O.U. Rio de Janeiro, 13 out. 1941 (retificado em 24 out. 1941). 
Presidência da República. Decreto n. 8.380, de 24 de dezembro de 2014. Concede indulto natalino e comutação de penas, e dá outras providências. D.O.U. Brasília, 24 dez. 2014a.

Presidência da República. Lei n. 7.209, de 11 de julho de 1984. Altera dispositivos do Decreto-Lei n. 2.848, de 7 de dezembro de 1940 - Código Penal, e dá outras providências. D.O.U. Brasília, 13 jul. 1984.

Presidência da República. Lei n. 10.216, de 6 de abril de 2001. Dispõe sobre a proteção e os direitos das pessoas portadoras de transtornos mentais e redireciona o modelo assistencial em saúde mental. D.O.U. Brasília, 9 abr. 2001.

Senado. Projeto de Lei do Senado n. 236/2012 (novo Código Penal). Diário do Senado Federal. Brasília, 10 jul. 2012. Disponível em: <http://www25.senado.leg.br/web/atividade/ materias/-/materia/106404>. Acesso em: 10 jan. 2016.

Supremo Tribunal de Justiça. Súmula 527: define tempo máximo de duração de medida de segurança. DJe, 18 maio 2015, RSTJ, v. 243, p. 1067.

Supremo Tribunal Federal. Habeas Corpus n. 84.219. São Paulo. Relator: Ministro Marco Aurélio, 16 ago. 2005. Disponível em: <http://redir.stf.jus.br/paginadorpub/paginador.jsp?docTP= AC\&docID=79519>. Acesso em: 17 maio 2017.

BRUNO, Aníbal. Perigosidade criminal e medidas de segurança. 4. ed. Rio de Janeiro: RIO, 1977.

CARVAlHO, Salo de. Antimanual de criminologia. 5. ed. São Paulo: Saraiva, 2013.

CONSELHO NACIONAL DE JUSTIÇA. Resolução n. 113, de 20 de abril de 2010. Dispõe sobre o procedimento relativo à execução de pena privativa de liberdade e de medida de segurança, e dá outras providências. Portal CNJ. Brasília, 2010. Disponível em: <http://www.cnj.jus.br/buscaatos-adm?documento $=2596>$. Acesso em: 20 jun. 2017.

CONSElHO NACIONAL DE POLÍTICA CRIMINAL E PENITENCIÁRIA. Resolução n. 4, de 30 de julho de 2010. Dispõe sobre as Diretrizes Nacionais de Atenção aos Pacientes Judiciários e Execução da Medida de Segurança. D.O.U. Brasília, 2 ago. 2010.

CORREIA, Ludmila Cerqueira. Avanços e impasses na garantia dos direitos humanos das pessoas com transtornos mentais autoras de delito. Dissertação (Mestrado em Ciências Jurídicas) - Universidade Federal da Paraíba, João Pessoa, 2007. 
; LIMA, Isabel Maria Sampaio Oliveira; ALVES, Vânia Sampaio. Direitos das pessoas com transtorno mental autoras de delitos. Cadernos de Saúde Pública. Debate, Rio de Janeiro, set., p. 1995-2002, 2007.

DINIZ, Debora. A custódia e o tratamento psiquiátrico no Brasil. Censo 2011. Brasília: Letras Livres, UnB, 2013.

FOUCAULT, Michel. História da loucura na idade clássica. Trad. José Teixeira Coelho Neto. 9. ed. São Paulo: Perspectiva, 2010.

GOFFMAN, Erving. Manicômio, prisões e conventos. Trad. Dante Moreira Leite. São Paulo: Perspectiva, 1974.

GOIÁS. Portaria n. 019/2006-GAB/SES. Secretária da Saúde de Goiás. D.O.E. Goiânia, 8 fev. 2006. Disponível em: <http://www.sgc.goias.gov.br/upload/links/arq_221_port0192006paili. pdf>. Acesso em: 20 jun. 2017.

GRACIA MARTíN, Luis. Principios rectores y presupuestos de aplicación de las medidas de seguridad y reinserción social en el derecho español. In: PRADO, Luiz Regis (Coord.). Direito penal contemporâneo: estudos em homenagem ao professor José Cerezo Mir. São Paulo: Revista dos Tribunais, 2007.

JACOBINA, Paulo Vasconcelos. Direito penal da loucura e reforma psiquiátrica. Brasília: ESMPU, 2008. . Sistema Único de Saúde e manicômio judiciário. Monografia (Curso de Especialização à Distância em Direito Sanitário para Magistrados e Membros do Ministério Público) - UnB e Fiocruz, 2003.

MARCHEWKA, Tânia Maria Nava. As contradições das medidas de segurança no contexto do direito penal e da reforma psiquiátrica. Ciências Penais, São Paulo, ano 1, n. 00, p. 173-189, 2004.

ORGANIZAÇÃO PAN-AMERICANA DE SAÚdE. Declaração de Caracas. Conferência Regional para a Reestruturação da Atenção Psiquiátrica na América Latina no Contexto dos Sistemas Locais de Saúde (SILOS). Caracas, Venezuela, 14 nov. 1990. Organização Mundial da Saúde, 1990.

PEREIRA, Maria Alice Ornellas. Representação da doença mental pela família do paciente. Interface-Comunicação, Saúde, Educação, v. 7, n.12, p. 71-82, 2003.

PERES, Maria Fernanda Tourinho; NERY FILHO, Antônio. A doença mental no direito penal brasileiro: inimputabilidade, irresponsabilidade, periculosidade e medida de segurança. História, Ciências, SaúdeManguinhos. Rio de Janeiro, v. 9, p. 335-355, maio-ago. 2002. 
PRADO, Alessandra Rapassi Mascarenhas. Adequação da legislação penal à Lei de Reforma Psiquiátrica: a internação como exceção. Ciências Penais, v. 13, p. 87-118, 2010.

PRADO, Luiz Regis. Curso de direito penal brasileiro. 11. ed. São Paulo: Revista dos Tribunais, 2012. v. 1.

QUEIROZ, Paulo. Direito penal: parte geral. Rio de Janeiro: Lumen Juris, 2010.

RIBEIRO, Bruno de Morais. Medidas de segurança. Porto Alegre: Sergio Antonio Fabris Editor, 1998.

SILVA, Martinho Braga Batista e. O desafio colocado pelas pessoas em medida de segurança no âmbito do Sistema Único de Saúde: a experiência do PAILI-GO. Physis Revista de Saúde Coletiva, Rio de Janeiro, v. 20, n. 2, p. 653-682, 2010.

TENÓRIO, Fernando. A reforma psiquiátrica brasileira, da década de 1980 aos dias atuais: história e conceitos. História, Ciências, Saúde. Manguinhos, Rio de Janeiro, v. 9, p. 25-59, jan.-abr. 2002.

WEIGERT, Mariana de Assis Brasil e. O discurso psiquiátrico na imposição e execução das medidas de segurança. In: CARVALHO, Salo de (Coord.). Crítica à execução penal. 2. ed. Rio de Janeiro: Lumen Juris, 2007.

Alessandra Mascarenhas Prado Mestra e Doutora em Direito pela PuC-SP. Professora de Direito Penal da Faculdade de Direito e do PPGD da UFBA E do CuRso de DiReito da UCSAL. Líder do GRupo dE Pesquisa Repensando o Direito Penal Contemporâneo.

armpradolayahoo.com.br

Danilo Schindler

Bacharel em Direito Pela UFBA. FoI PESquisador PIBIC/CNPQ. Mestrando em Direito Penal no PPGD/UFBA. Advogado.

schindlerdanilolgmail.com 